\title{
Simulación de situaciones urgentes en Atención Primaria (taller instrumentalizado)
}

\author{
M. Nieto Moro, E. Pérez Suárez
}

Monserrat Nieto Moro: montsen@hotmail.com

Servicio de Cuidados Intensivos Pediátricos. Hospital Infantil Universitario Niño Jesús, Madrid. España.

El conocimiento del manejo de situaciones de emergencia es fundamental para todo pediatra, debido a que el pronóstico de un niño grave depende e la asistencia recibida en las primeras horas de su enfermedad. Dada la escasa frecuencia de esta patología en el ámbito extrahospitalario, sería útil disponer de una sistemática de actuación que permitiera mejorar el proceso de toma de decisiones, optimizar los recursos y aumentar la seguridad del paciente. La simulación médica avanzada constituiría un recurso fundamental para el entrenamiento de los profesionales en la atención de la emergencia pediátrica.

El objetivo principal del taller es enfocar de una manera práctica la evaluación, estabilización y tratamiento de las urgencias vitales pediátricas que, debido a su poca frecuencia, requieren seguridad y rapidez en la toma de decisiones. Para ello se dispondrá de un simulador pediátrico con capacidad para imitar los signos clínicos más relevantes y permitirá a los alumnos afrontar distintas situaciones clínicas críticas en las que tendrán que realizar un diagnóstico y tratamiento. Posteriormente se revisarán los casos clínicos, permitiendo a los participantes reflexionar y aprender de su propia experiencia, proporcionando un nue- vo método de aprendizaje y entrenamiento en el que se entrelazan conocimientos, habilidades y factores humanos.

\section{VALORACIÓN INICIAL EN UNA SITUACIÓN URGENTE}

La evaluación inicial de un paciente pediátrico se puede dividir en una primera impresión visual y auditiva general, y en segundo lugar la evaluación práctica del $A B C D$. La valoración rápida inicial se puede realizar en muy pocos segundos mediante el triángulo de evaluación pediátrica, permitiendo identificar alteraciones funcionales y anatómicas, determinar la gravedad del trastorno y la urgencia con la que se requiere intervenir. Se evalúa el estado neurológico mediante la apariencia del niño; es decir, si está alerta, cómo interacciona, su tono muscular o si tiene un llanto consolable. Para la función respiratoria se valora si el niño presenta signos de dificultad respiratoria, ruidos respiratorios anormales o posturas anómalas. Y el estado circulatorio queda reflejado mediante el color de la piel: palidez, cianosis o cutis reticular. Tras la evaluación inmediata se puede hacer un diagnóstico de la situación: paciente estable o por el contrario 
presenta dificultad respiratoria, shock o disfunción del sistema nervioso central.

Ante un paciente inestable, lo prioritario es optimizar el "ABCD" que se basa en el acrónimo: " $A$ " de vía aérea, " $B$ " de ventilación, " $C$ " de circulatorio y " $D$ " de neurológico. El " $A B C D$ " permite identificar de los problemas que suponen una amenaza vital e instaurar las medidas terapéuticas oportunas. En primer lugar se debe realizar la valoración de la permeabilidad de la vía aérea (A) y si el niño no la puede mantener espontáneamente abierta se procederá a su apertura mediante la maniobra de tracción mandibular, la triple maniobra o la maniobra frente-mentón; para posteriormente considerar la apertura instrumental de la vía aérea mediante una cánula orofaríngea e incluso, si estas medidas no son suficientes, con la intubación endotraqueal. A continuación se comprobará la función ventilatoria (B) teniendo en cuenta la frecuencia respiratoria (taquipnea, bradipnea), la amplitud de la respiración, el esfuerzo respiratorio, la auscultación, la coloración central y la pulsioximetría; y se administrará oxígeno suplementario para optimizar el aporte a los tejidos. Si no se consigue una adecuada oxigenación y/o ventilación, se iniciará ventilación manual con bolsa y mascarilla. La tercera prioridad es el sistema circulatorio (C), que se evalúa mediante la exploración de pulsos centrales y periféricos, color y temperatura de piel, relleno capilar y búsqueda de posibles hemorragias. Será necesario monitorizar la tensión arterial, el ritmo cardiaco y canalizar una vía venosa para mantener la estabilidad hemodinámica y/o administrar fármacos. Así mismo, la determinación de una glucemia capilar formará parte de la evaluación inicial de un paciente pediátrico crítico. Por último, la valoración inicial del paciente grave debe incluir el nivel de conciencia (D), que se valora con la escala de coma Glasgow y con la exploración del tamaño y reactividad pupilar.

Tras completar el ABCD, se comenzará con un examen físico general. Si es posible y de forma simultánea, un segundo médico realizará una historia clínica rápida acerca del episodio actual y de los antecedentes del paciente, con el objetivo de in- tentar averiguar la causa y poder aplicar un tratamiento específico.

\section{ESTABILIZACIÓN DE UN PACIENTE CON ALTERACIÓN HEMODINÁMICA}

El shock se define como un estado patológico en el que existe una entrega insuficiente de oxígeno y nutrientes a los tejidos debido a una disminución de la perfusión tisular. Los signos y síntomas se derivan del fallo en la función de los órganos afectados, del tipo de shock y de la gravedad del mismo. El diagnóstico del shock es clínico y se basa en los signos de hipoperfusión tisular. La taquicardia y la taquipnea son inespecíficas y aparecen precozmente. La taquicardia es un dato constante en el shock que tiene como objeto aumentar el gasto cardiaco, pero la hipotensión arterial (tensión arterial sistólica inferior a edad en años $\times 2+70$ ) es un signo tardío que indica un estado avanzado del shock. Siempre se deben evaluar los pulsos centrales y periféricos, pues la ausencia de pulsos periféricos o un pulso filiforme indican un shock descompensado. También se debe explorar la temperatura de la piel, el relleno capilar (normal $\leq 2$ segundos) y el nivel de conciencia, que suele estar disminuido por hipoperfusión cerebral.

Los efectos del shock son inicialmente reversibles; sin embargo, si no se corrige la hipoxia tisular se producen cambios celulares que conducen al fallo de órganos. El objetivo de la estabilización inicial $(A B C)$ es restablecer una adecuada perfusión y oxigenación tisular lo más rápidamente posible para evitar el daño tisular. Es fundamental optimizar el transporte de oxígeno al organismo mediante la administración de oxígeno, manteniendo una saturación de oxígeno $\left(\mathrm{SatO}_{2}\right)>95 \%$, inicialmente con gafas nasales y si fuera necesario con bolsa-reservorio. La intubación endotraqueal será necesaria cuando exista hipoxemia a pesar de las medidas anteriores, hipoventilación o shock persistente. Para intentar corregir el volumen circulatorio se intentará la canalización de dos vías periféricas para comenzar expansión con fluidos. La expansión de 
la volemia se realizará con cristaloides isotónicos en bolos de $20 \mathrm{ml} / \mathrm{kg}$ en el menor tiempo posible, ya que la reposición rápida puede frenar la cascada de cambios inflamatorios tisulares producidos por la hipoperfusión mejorando el pronóstico. Si el paciente no mejora se puede repetir la infusión de líquidos; pero la falta de respuesta al volumen indicaría la necesidad de iniciar un soporte con fármacos inotrópicos.

La vigilancia y monitorización de estos pacientes debe ser continua; incluyendo electrocardiograma, tensión arterial, pulsioximetría, nivel de conciencia, color de piel, frialdad y relleno capilar.

\section{ESTABILIZACIÓN DE UN PACIENTE CON INSUFICIENCIA RESPIRATORIA}

El compromiso de la vía aérea y de la ventilación es una de las causas más frecuentes de patología grave en Pediatría. La evaluación inicial de estos pacientes seguirá los mismos pasos que se han comentado anteriormente.

\section{Dificultad respiratoria alta}

\section{Laringitis aguda}

Su etiología es viral, siendo los virus parainfluenza 1 y 2 los patógenos más frecuentes. Se produce una inflamación de la vía aérea extratorácica que conlleva una obstrucción de la misma, dando lugar a la tríada típica de tos perruna, disfonía y estridor inspiratorio.

Se debe tranquilizar al niño, procurando no explorar la orofaringe si el niño no colabora. En la laringitis leve se recomiendan medias generales y se puede valorar la administración de una dosis única de dexametasona oral a 0,15 mg/kg para disminuir la tos y la disfonía.

En la laringitis moderada (estridor en reposo con tiraje leve, hipoventilación leve y $\mathrm{SatO}_{2} \geq 95 \%$ ) se indicará una dosis única de dexametasona oral a $0,15 \mathrm{mg} / \mathrm{kg}$, manteniendo al paciente en observación durante 1-3 horas. La dexametasona oral se absorbe rápidamente, con igual efectividad que la vía intramuscular, por lo que se considera la vía de elección. La prednisolona se emplearía a dosis equivalentes a la dexametasona, pero sería un esteroide de segunda elección. Si el paciente vomita, se puede administrar la dexametasona por vía intramuscular o se podría sustituir por una dosis de $2 \mathrm{mg}$ de budesonida nebulizada.

La laringitis grave (estridor en reposo con tiraje moderado-grave, hipoventilación moderada-grave y $\mathrm{SatO}_{2} \leq 94 \%$ ) debe ser trasladada a un centro hospitalario, aunque previamente se administrará dexametasona oral $(0,6 \mathrm{mg} / \mathrm{kg})$ y L-adrenalina nebulizada (3 mg) con oxígeno a flujos bajos (4-6 I/ min). La adrenalina tendrá su efecto máximo a los 30 minutos y una duración de acción de dos horas, por lo que se debe tener al paciente en observación durante al menos tres horas para detectar la reaparición de los síntomas y nunca se debe administrar sin asociar corticoides orales.

La mayoría de los pacientes con laringitis pueden ser dados de alta al domicilio y solo deberían ser remitidos al centro hospitalario aquellos pacientes con dificultad respiratoria moderada que no mejoran tras el tratamiento inicial y todos los pacientes con dificultad respiratoria grave.

\section{Dificultad respiratoria baja}

La primera medida de todo paciente con una insuficiencia respiratoria baja es la administración de oxígeno para mejorar la hipoxia, utilizando el dispositivo adecuado para aportar la concentración de oxígeno necesaria para una $\mathrm{SatO}_{2}>93 \%$. Se monitorizará la frecuencia respiratoria, puesto que es la constante que mejor valora la dificultad respiratoria, así como la frecuencia cardiaca, la tensión arterial y la saturación de oxígeno. Los signos indicativos de gravedad son: taquipnea superior a $60 \mathrm{rpm}$, bradipnea, gasping, apnea, hipoventilación, cianosis, hipotonía o alteración del nivel de conciencia.

\section{Asma}

Los objetivos del tratamiento de la crisis asmática son mantener una adecuada oxigenación 
$\left(\mathrm{SatO}_{2}>93 \%\right)$, disminuir la obstrucción del flujo aéreo con los broncodilatadores inhalados y reducir la inflamación de la vía aérea y prevenir la recaída con la administración precoz de corticoides sistémicos. Ante una crisis asmática se debe realizar una anamnesis rápida con el objetivo de valorar la intensidad de la crisis y predecir la respuesta al tratamiento (tiempo desde el inicio de los síntomas, tratamiento recibido antes de la visita y respuesta al mismo), identificar a los pacientes con riesgo de asma fatal e identificar desencadenantes (alérgenos, tóxicos, infecciones...). Y para la valoración de la gravedad de la crisis se utilizará el Pulmonary Score y la saturación de oxígeno.

El salbutamol es un $\beta_{2}$-adrenérgico de acción corta y es el fármaco de primera elección en la crisis asmática. Se puede dar con inhaladores presurizados con cámara espaciadora y se nebulizará en el caso de pacientes que no traen su sistema de inhalación y crisis de asma moderadas o graves que precisen oxígeno.

El bromuro de ipratropio está indicado en crisis moderadas y graves, y siempre debe emplearse asociado a $\beta_{2}$-adrenérgicos de acción corta. Se ha demostrado que su uso en niños mayores de dos años reduce la tasa de ingresos.

Los corticoides sistémicos están indicados en las crisis moderadas-graves. Su precocidad en la administración mejora la respuesta al tratamiento. Preferentemente, se administran por vía oral porque es tan efectiva como la parenteral, y la vía intravenosa se reservará para pacientes con crisis asmáticas refractarias al tratamiento o cuando no exista tolerancia oral.

\section{ESTABILIZACIÓN DEL PACIENTE CON DISMINUCIÓN DEL NIVEL DE CONCIENCIA}

La alteración aguda del nivel de conciencia puede tener múltiples etiologías y puede suponer un compromiso vital para el niño. La primera medida para su estabilización será la evaluación ordenada de las funciones vitales siguiendo el $A B C D$, siendo muy conveniente la participación inicial de un segundo médico que realice una historia clínica básica.
En todo paciente con disminución del nivel de conciencia, una vez comprobada la vía aérea, la ventilación y la estabilidad hemodinámica, es necesario realizar una determinación de la glucemia capilar, puesto que la hipoglucemia es una causa muy frecuente de decaimiento o disminución del nivel de conciencia en niños (sobre todo en los lactantes). En caso de no existir hipoglucemia no se deben administrar líquidos hiposmolares, por el riesgo de edema cerebral.

El objetivo de un paciente con disminución del nivel de conciencia es mantener en todo momento un adecuado estado de oxigenación y hemodinámico. Por lo tanto, hasta la llegada del Servicio de Emergencias se asegurará la vía aérea, se administrará oxígeno al $100 \%$ con mascarilla y se mantendrá al paciente monitorizado con una reevaluación constante hemodinámica, respiratoria y neurológica (escala de coma de Glasgow, pupilas y signos de focalidad neurológica). La intubación endotraqueal se indicará cuando exista incapacidad para mantener la vía aérea permeable, en caso de hipoxemia o hipoventilación, puntuación en la escala de coma de Glasgow inferior a 9, ausencia de reflejos nauseoso y/o faríngeo o signos de herniación cerebral.

\section{Tratamiento etiológico}

\section{Crisis convulsiva}

Las convulsiones son frecuentes en los pacientes con coma, a veces son muy sutiles (movimientos labiales, desviación de la mirada, nistagmo), por lo que ante la duda se debe comenzar el tratamiento con fármacos antiepilépticos. El tratamiento de las crisis epilépticas se basa en el empleo secuencial de fármacos, siendo las benzodiazepinas los fármacos de primera elección.

\section{Intoxicación}

Se debe sospechar ante cuadros de comienzo agudo con afectación del nivel de conciencia o con síntomas extraños. El uso de lavado gástrico como método de descontaminación intestinal es contro- 
vertido, pues su eficacia disminuye si la ingesta ha ocurrido hace más de una hora, y aunque se realice en la primera hora solo suele evacuar el 30-40\% del tóxico. Además, por el riesgo de aspiración, solo se realizará en pacientes conscientes o con intubación endotraqueal para proteger la vía aérea. Por tanto, su principal indicación es la necesidad de extraer un tóxico potencialmente grave-letal en un paciente que es atendido en menos de una hora desde la ingesta. El carbón activado muestra también su máxima eficacia cuando se administra en la primera hora tras la ingesta y se contraindica en pacientes con alteración del nivel de conciencia.

\section{Hipertensión intracraneal}

Puede ser reflejo de tumores, traumatismos craneoencefálicos, hidrocefalia o hemorragia cerebral.
Se debe sospechar hipertensión intracraneal grave con signos de enclavamiento en aquellos pacientes que presenten una triada de Cushing consistente en hipertensión arterial, bradicardia y bradipnea, que puede estar acompañada de anisocoria secundaria a compresión del III par craneal por una herniación transtentorial uncal.

\section{CONFLICTO DE INTERESES}

Las autoras declaran no presentar conflictos de intereses en relación con la preparación y publicación de este artículo.

\section{ABREVIATURAS}

SatO $_{2}$ : saturación de oxígeno.

- García Herrero MA, González Cortes R. Triángulo de Evaluación Pediátrica. Rev Pediatr Aten Primaria. 2011; 20 Supl: S193-6.

- Auerbach M, Kessler D, Foltin JC. Repetitive pediatric simulation resuscitation training. Pediatr Emerg Care. 2011;27:29-31.

- Berg MD, Schexnayder SM, Chameides L, Terry M, Donoghue A, Hickey RW, et al. Pediatric Basic Life Support: 2010 American Heart Association. Guidelines for Cardiopulmonary Resuscitation and Emergency Cardiovascular Care. Circulation. 2010;122:5862-75.

- Bjomson CL, Johnson DW. Croup. Lancet. 2008;371: 329-39.

- Brierley J, Carcillo JA, Choong K, Cornell T, Decaen A, Deymann A, et al. Clinical practice parameters for hemodynamic support of pediatric and neonatal septic shock: 2007 update from the American College of Critical Care Medicine. Crit Care Med. 2009. 37:666-88.
- García R, Martínez de Azagra A. Disminución aguda del nivel de conciencia. Enfoque del niño en coma. En: Flores J, Serrano A (eds.). Urgencia y tratamiento del niño grave. Madrid: Ergon; 2007. p. 461-8.

- GEMA 2009. Guía española para el manejo del asma [en línea]. Disponible en: www.gemasma.com/ima ges/stories/GEMASMA/Documentos/GEMA\%20 2009/index.html

- Luten R, Rothrock SG. Approach to resuscitation and advance life support for infants and children. Pediatric Emergency Medicine. Philadelphia; Saunders Elsevier; 2008. p. 3-12.

- Ortiz-Alvarez O, Mikrogianakis A; Canadian Paediatric Society, Acute Care Committee. Managing the paediatric patient with an acute asthma exacerbation. Paediatr Child Health. 2012;17:251-62. 